\title{
Biclonal myelodysplastic syndrome involving six chromosomes and monoallelic loss of RB1 - A rare case
}

\author{
Walid Al-Achkar ${ }^{1 *}$, Abdulsamad Wafa ${ }^{1}$, Elisabeth Klein $^{2}$ and Abdulmunim Aljapawe ${ }^{3}$
}

\begin{abstract}
Background: Myelodysplastic syndrome (MDS) represents a group of clonal hematological disorders characterized by progressive cytopenia, and reflects to defects in erythroid, myeloid and megakaryocytic maturation. MDS is more frequently observed in older aged patients with cytogenetic abnormalities like monosomy of chromosome(s) 5 and/or 7. In 50\% of de novo MDS cases, chromosomal aberrations are found and rearrangements involving the retinoblastoma (RB1) gene in $13 q 14$ are found.

Results: Here, we are presenting a case report of a rare biclonal MDS with a karyotype of $45, X Y,-4$, der(6)t( $(4 ; 6)$ (p15.1;p21.3), der(8)t(4;8)(q31.2;q22), t(13;16)(q21.3;p11.2)[11]/45, XY, der(7)t(7;13)(p22.2 22.3;q21.3),-13 [9]. The patient was diagnosed according to WHO classification as refractory anemia with excess of blasts (RAEB-II). Immunophenotyping was positive for CD11b, CD11c, CD10, CD13, CD15, CD16 and CD33.

Conclusion: We report, a novel and cytogenetically rare case of a biclonal MDS with complex chromosomal aberrations and deletion of RB1-gene in both clones. These findings are associated with a poor prognosis as the patient died 3 months after diagnosis.
\end{abstract}

\section{Background}

Myelodysplastic syndrome (MDS) refers to a group of clonal acquired diseases characterized by trilineage defects in erythrocytic, granulocytic, and megakaryocytic lineages of hematopoiesis. Although considerable as a clonal malignancy of its own, MDS is sometimes classified as a premalignant condition, which progresses to acute myeloid leukemia (AML) regularly [1]. Overall, MDS affects approximately 1 in 500 persons over 60 years of age, making it the most common hematologic malignancy in this age group [1].

Cytogenetic abnormalities are found in $\sim 50 \%$ of the patients with de novo MDS and the most commonly involved chromosomal changes observed are monosomy 5 and/or 7, trisomy 8 and/or partial deletion in $5 q, 7 q$, $9 q$ and $20 q$ [2,3]. Unbalanced translocations are also frequently found, and they are usually detected as a part of

\footnotetext{
* Correspondence: ascientific@aec.org.sy

${ }^{1}$ Molecular Biology and Biotechnology Department, Human Genetics

Division, Atomic Energy Commission, Damascus, Syria

Full list of author information is available at the end of the article
}

complex karyotypes, associated with loss of chromosomal material, and related to disease progression [4].

Deletions or translocations involving chromosomal band 13q14, the locus of the retinoblastoma (RB1) gene, are observed in a variety of hematological malignancies including myelofibrosis (MF), MDS, AML, chronic myelogenous leukemia (CML) and chronic lymphocytic leukemia (CLL) [4]. Recently, it has been shown that deletions of 13q14 are detected at a high frequency (more than 40\%) in cases of CLL and multiple myeloma (MM) by fluorescence in situ hybridization (FISH) analyses [4].

We are presenting a new case of a biclonal MDS case with yet unreported translocation events involving six different chromosomes and a monoallelic loss of $R B 1$ in both clones. In this case, multicolor banding (MCB) technique was found very useful for characterizing the breakpoints involved in the chromosomal rearrangements in this case. 


\section{Case report}

In June 2009, a 60 year old male patient was referred with anemia, thrombocytopenia, loss of weight and fever. His white blood cell count was $7 \times 10^{9} / \mathrm{l}$, with $64.5 \%$ neutrophils, $24.6 \%$ lymphocytes, $4.2 \%$ monocytes, $1 \%$ eosinophiles, $1 \%$ basophils and $4.6 \%$ blast. Bone marrow was hypercellular with $19 \%$ blast cells. Dysplastic changes in bone marrow included cytoplasmic hypogranulation of neutrophils, erythroblasts and micromegakaryocytes. The red blood cell count was $3.38 \times 10^{6} / \mathrm{cmm}$ with $8.3 \mathrm{~g} / \mathrm{dl}$ hemoglobin level along with platelet count of $49 \times 10^{9} / \mathrm{l}$, and LDH value of $571 \mathrm{U} / \mathrm{l}$. Physical examination of the patient showed splenomegaly. The patient was treated with Zyloric ( $300 \mathrm{mg}$ as a daily dose) and Hydroxyurea (500 $\mathrm{mg}$ as a daily dose) for 1 month and later continued on Hydroxyurea (500 mg as a daily dose) for 3 month. The patient died 3 months after diagnosis.

Karyotyping was done after the initiation of the treatment which showed a mosaic and biclonal karyotype with $45, \mathrm{XY},-4, \operatorname{der}(6) \mathrm{t}(4 ; 6)(? ; ?), \operatorname{der}(8) \mathrm{t}(4 ; 8)(? ; ?), \mathrm{t}(13 ; 16)$ (?;?)/45, XY, der(7)t(7;13)(?;?),-13 (Figure 1), which was further studied by molecular cytogenetics (Figure 2, 3, 4). Dual-color-FISH using WCP and CEP probes specific for chromosomes 4, 6, 7, 8, 13 and 16 confirmed the translocation seen in GTG-banding. Application of subtelomeric probes for 7 pter and 7qter revealed two signals of subtelomeric 7 qter on both homologous chromosomes 7 and one signal of subtelomeric 7 pter on intact chromosome 7. Thus, subtelomeric region 7 pter was deleted on the derivative chromosome 7 (Figure 2). Applying an RB1-specific probe showed one signal only on the normal chromosome 13 in both clones. The analysis using MCB probes specific for individual chromosome involved in translocation, determined the breakpoint location and the final karyotype was found to be with $45, \mathrm{XY},-4, \operatorname{der}(6) \mathrm{t}(4 ; 6)(\mathrm{p} 15.1 ; \mathrm{p} 21.3), \operatorname{der}(8) \mathrm{t}$ $(4 ; 8)(\mathrm{q} 31.2 ; \mathrm{q} 22), \mathrm{t}(13 ; 16)(\mathrm{q} 21.3 ; \mathrm{p} 11.2)[11] / 45, \mathrm{XY}, \operatorname{der}(7) \mathrm{t}$ $(7 ; 13)(\mathrm{p} 22.2 \sim 22.3 ; \mathrm{q} 21.3),-13$ [9].

Immunophenotyping of peripheral blood characterized the neutrophiles which showed abnormal side scatter pattern, as well as abnormal intensity staining patterns for $\mathrm{CD} 11 \mathrm{~b}(63 \%), \mathrm{CD} 11 \mathrm{c}(59.3 \%), \mathrm{CD} 10(17.4 \%), \mathrm{CD} 13$ (44\%), CD15(59.3\%), CD16(46\%) and CD33(20.4\%). The majority of monocytes were HLADr+ (4.2\%). Lymphocyte subsets percentages were low. The patient was diagnosed as having common MDS, refractory anemia with excess of blasts (RAEB) in the French-American-British (FAB) classification, or RAEB-II in the World Health Organization (WHO) classification [5].

\section{Discussion}

We described a biclonal MDS case with cytogenetic rearrangements involving six different chromosomes together with a monoallelic loss of the RB1 gene in both clones.

The Cancer Genome Anatomy Project databases (http://cgap.nci.nih.gov/Chromosomes/AbnCytSearchForm) and atlas of genetics and cytogenetics in oncology and hematology (http://atlasgeneticsoncology.org/) showed not a single case of MDS with a $\operatorname{der}(6) t(4 ; 6)$ (p15.1;p21.3), a der(7)t(7;13)(p22.2 22.3;q21.3), a der(8)t $(4 ; 8)(\mathrm{q} 31.2 ; \mathrm{q} 22)$, or a $\mathrm{t}(13 ; 16)(\mathrm{q} 21.3 ; \mathrm{p} 11.2)$. Contrarily the involvement of $R B 1$ gene in MDS is known and appears to be a rare event [4]. The RB1 protein acts as a cell cycle regulator which blocks the transition of normal cells from G0/G1 into S phase of the cycle. Mice with homozygous disruption of the RB1 alleles resulted in an overall normal development but had lethal anemia, suggesting a critical role of the RB1 gene in erythropoiesis [4]. In the present case, anemia and thrombocytopenia were predominantly observed during the clinical course, while white blood cells count was relatively preserved. This impaired erythropoiesis might be related to monoallelic loss of the RB1 gene [4].

Besides imbalances of chromosomes 13, the observed rearrangements lead to a partial monosomy 4 p15.1 to $4 \mathrm{q} 31.2$ in the slightly larger of both clones. In accordance with the international prognostic scoring system (IPSS) classification of chromosomes 4 and 13 loss in a RAEB-II stage patient supports an intermediate- 2 prognosis group and/or poor prognosis group [6,7].

The decreased heterogeneous expression of those antigens was consistent with myelodysplastic disease in transition.

Concerning the additional observed acquired imbalances, up to present somehow similar minor terminal deletions of $6 \mathrm{p} 21.3$ in malignant hematological disorders was observed, and an involvement of the breakpoint $8 \mathrm{q} 22$ in an oncogene induced solid tumor $[8,9]$. Deletions of $7 p$ confer an inferior outcome in children with ALL, regardless of the presence of other poor prognostic features. Monosomy 7 is also associated with inferior event-free survival (EFS) in children with ALL [10]. 13q21.3 region was involved in CLL cases and 16p11.2 region was found in classical Hodgkin lymphoma but to our knowledge our breakpoints have not been reported in MDS, yet $[11,12]$.

According to a recent study, the LDH level was nearly as powerful as a prognostic parameter as karyotyping and an elevated LDH was associated with poor prognosis in MDS [13]. The LDH level for the presented patient was $571 \mathrm{U} / \mathrm{l}$, which compared to the normal value (up to $480 \mathrm{U} / \mathrm{l}$ ) is enhanced. Thus, also the $\mathrm{LDH}$ level as well as cytogenetics supported an adverse prognosis, which unfortunately was confirmed by the clinical outcome. 


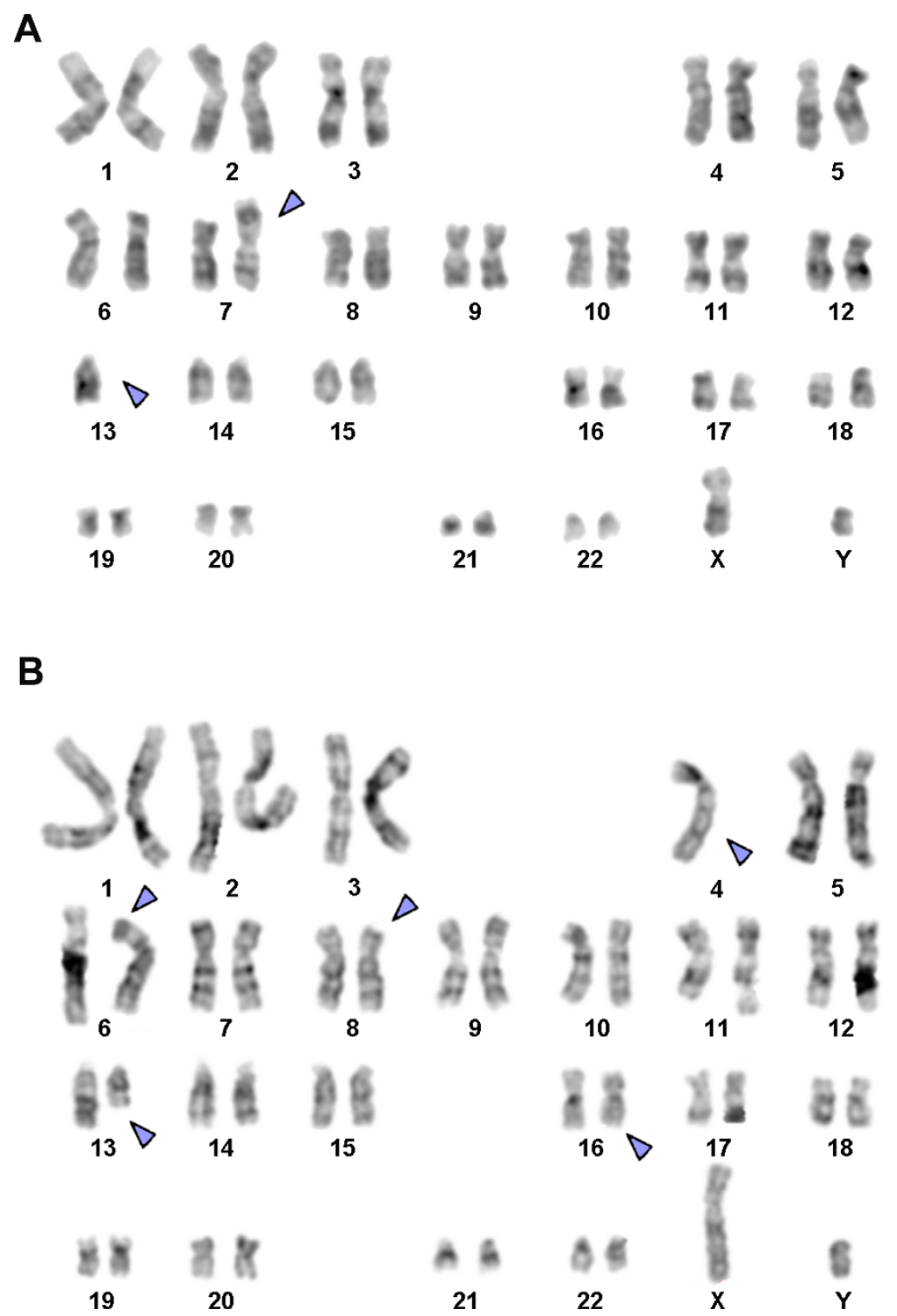

Figure 1 GTG-banding revealed a biclonal condition in the present case. All derivative chromosomes are marked by an arrow head. (A) A translocation between chromosomes 7, 13 and loss of one chromosome 13 was observed. (B) A complex karyotype involving the chromosomes $4,6,8,13$ and 16 .

In conclusion, here we reported a novel translocation involving six chromosomes distributed in two clones and monoallelic loss of RB1 in both clones. Our finding and according to WHO classification, IPSS and LDH is considered to a poor prognostic factor in MDS patients, as no response was observed after the application of chemotherapy.

\section{Materials and methods}

\section{Chromosome analysis}

Chromosome analysis using GTG-banding was performed according to standard procedures [14]. Twenty metaphases derived from unstimulated bone marrow of the patient were analyzed. Karyotypes were described according to the International System for Human Cytogenetic Nomenclature [15].

\section{Molecular cytogenetics}

Fluorescence in situ hybridization (FISH) using whole chromosome painting (WCP) probe for chromosomes 4, 6, 7, 13 and 16 (MetaSystems/Germany) and subtelomeric probes for 7pter and 7qter (Abbott Molecular/ Vysis, USA) were applied according to manufacturer's instructions together with a chromosome enumeration 


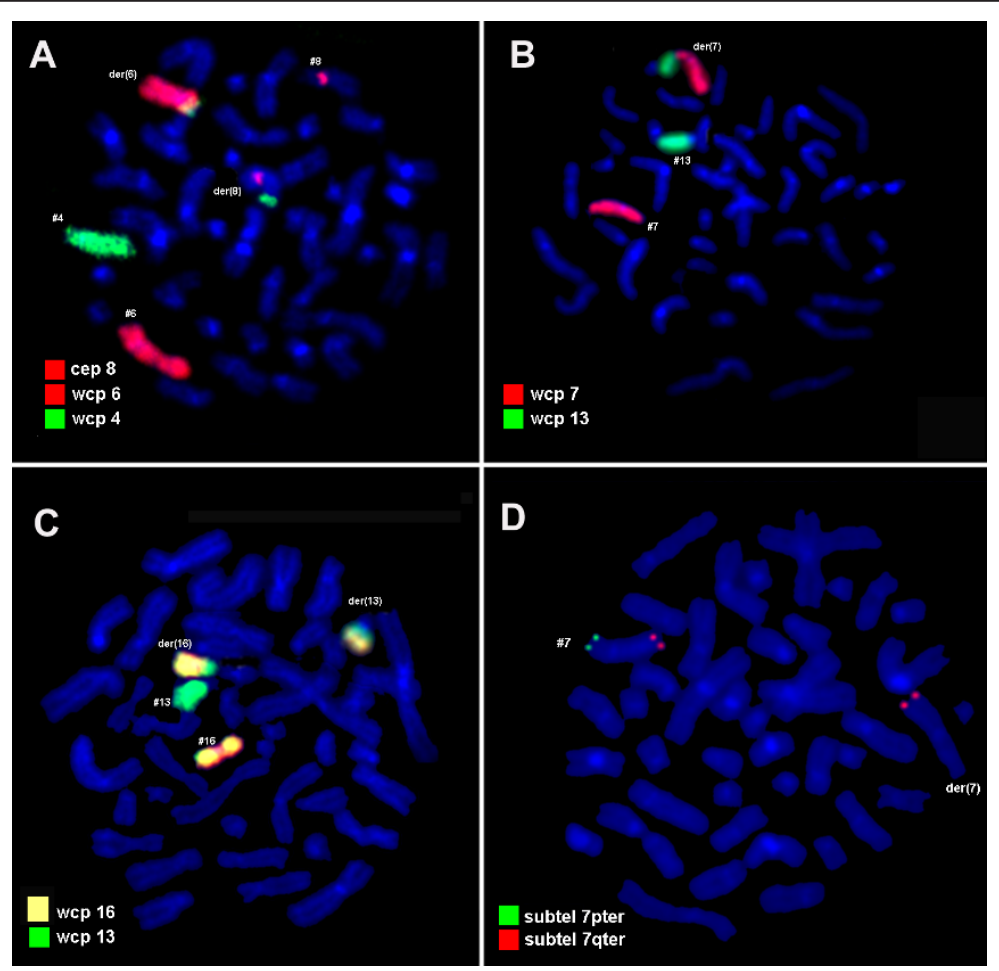

Figure 2 Karyotype and chromosomal aberrations were confirmed using molecular cytogenetic approach. (A) The translocation among chromosomes 4, 6 and 8 were identified using WCP for chromosomes 4 and 6 (MetaSystems, Altlussheim, Germany) mixed with CEP 8 (Abbott Molecular/Nysis, USA). (B) The translocation between chromosomes 7 and 13 was identified using WCP for chromosomes 7 and 13 (MetaSystems, Altlussheim, Germany). (C) The translocation between chromosomes 13 and 16 was identified using WCP for chromosomes 13 and 16

(MetaSystems, Altlussheim, Germany). (D) The subtelomeric deletion of chromosome 7 was identified using subtelomeric 7 pter and subtelomeric 7qter (Abbott Molecular/Nysis, USA). Abbreviations: \#, chromosome; der, derivative chromosome.

probe (CEP) for chromosome 8 and specific probe for RB1 (LSI 13 (RB1) Abbott Molecular/Vysis, USA) [14]. Multicolor banding probe (MCB) sets based on microdissection derived region-specific libraries for chromosome $4,7,13$ and 16 were applied as previously described [16]. Twenty metaphase spreads were analyzed, each using a fluorescence microscope (AxioImager.Z1 mot, Zeiss) equipped with appropriate filter sets. Image capturing and processing were carried out using an Isis mFISH imaging system (MetaSystems, Altlussheim, Germany).

\section{Immunophenotyping}

Immunophenotyping of leukemic blasts was done using general panel of fluorescent antibodies against the following antigens typical for different cell lineages and cell types: CD1a, CD2, CD3, CD4, CD5, CD8, CD10, CD11b, CD11c, CD13, CD14, CD15, CD16, CD19, CD20, CD22, CD23, CD32, CD33, CD34, CD38, CD41a, CD45, CD56, CD57, CD64, CD103, CD117, CD123, CD209, CD235a and CD243; In addition to antibodies to Kappa and Lambda light Chains, sIgD, sIgM, and HLADr. All antibodies were product from BD

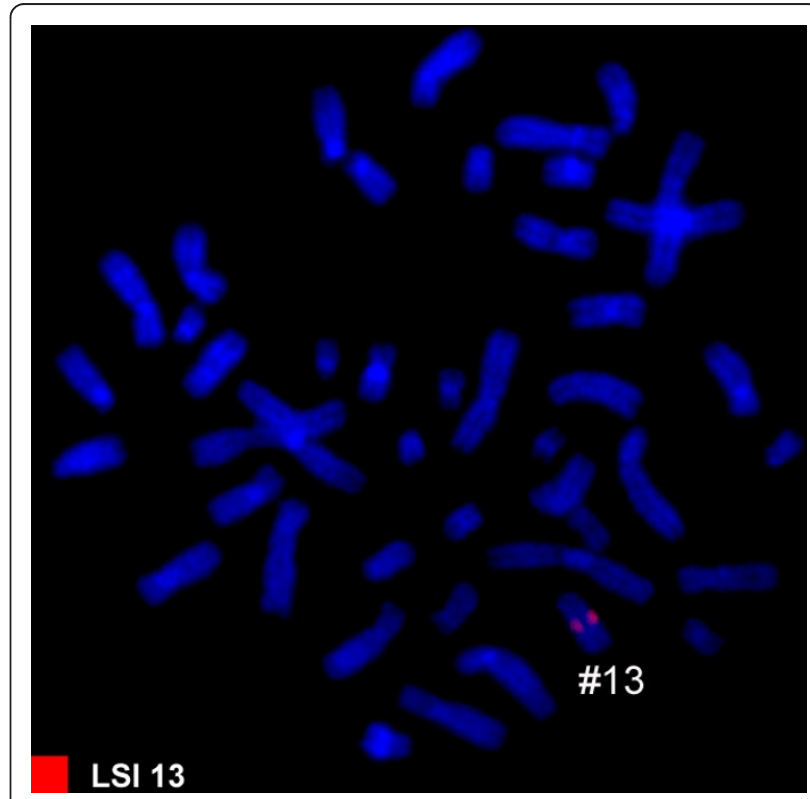

Figure 3 Fluorescence in situ hybridization (FISH) using probe for RB1 gene on metaphase spread showed one RB1 signal on normal chromosome 13 in the second clone. Abbreviations: \#, chromosome. 

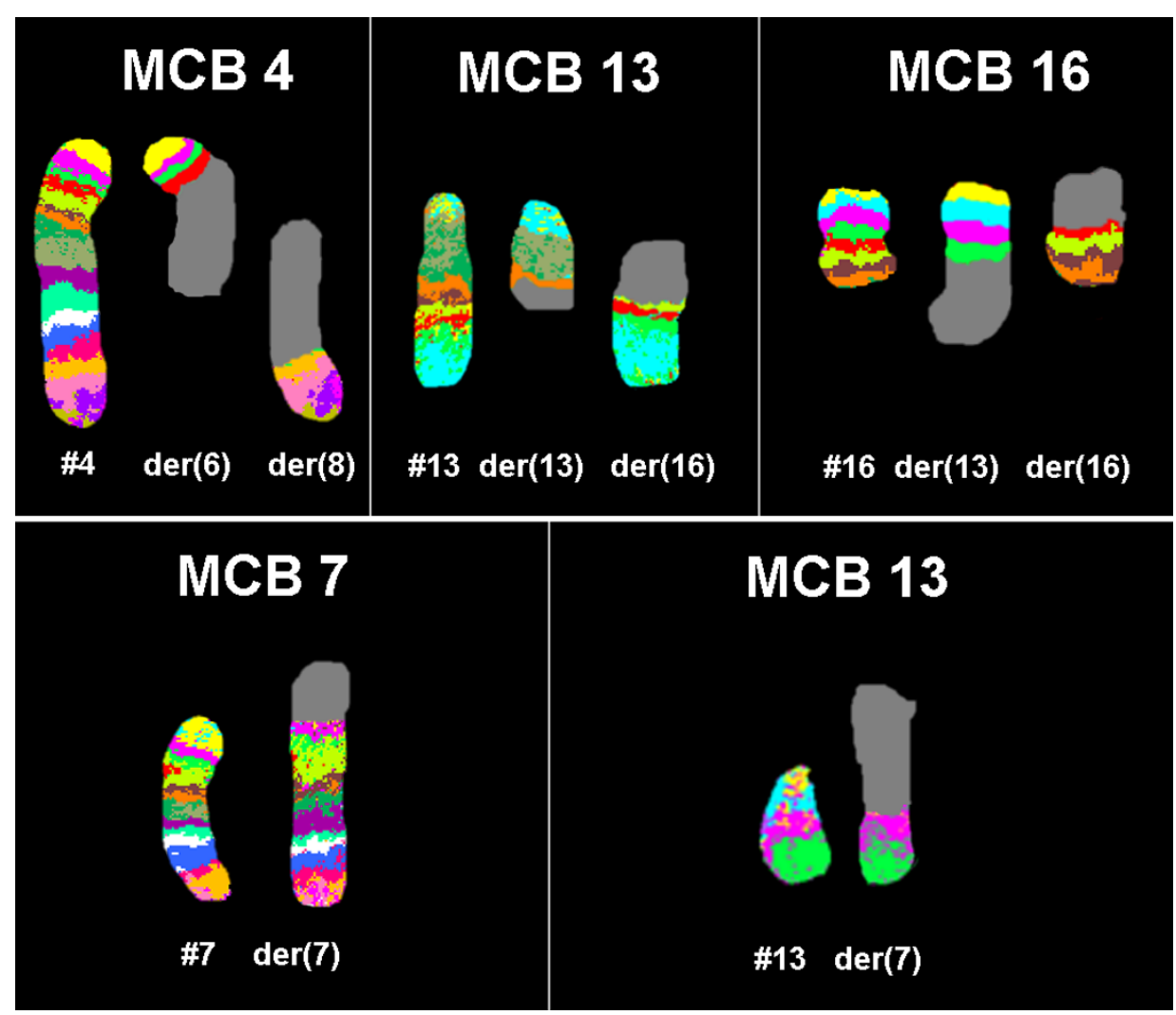

Figure 4 Multicolor banding (MCB) was applied to determine which chromosomes were involved in the chromosomal aberrations Each image shows the results of MCB analysis using probe sets for chromosomes 4, 7, 13 and 16. The normal chromosomes are shown in the left side of each image and the derivative of the four chromosomes on the right side of normal chromosomes. The MCB-probes unstained regions on the derivative chromosomes are shown in gray. \#, chromosome; der, derivative chromosome.

Biosciences. Four-color immunophenotyping on peripheral blood specimen was performed. Samples stained and analyzed on a BD FACSCalibur ${ }^{\mathrm{TM}}$ flow cytometer according to $\mathrm{BD}$ Biosciences manuals and products insert sheets. Autofluorescence, viability, and isotype controls were included. Flow cytometric data acquisition and analysis conducted by BD Cellquest ${ }^{\mathrm{TM}}$ Pro software.

\section{Consent}

Written informed consent was obtained from the patient for publication of this case report and accompanying images. A copy of the written consent is available for review by the Editor-in-Chief of this journal.

\section{Acknowledgements}

We thank Prof. I. Othman, the Director General of Atomic Energy

Commission of SYRIA (AECS) and Dr. N. Mirali, Head of Molecular Biology and Biotechnology Department for their support. This work was supported by the AECS, in parts by the Stefan-Morsch-Stiftung and the DAAD (D/07/ 09624).

\section{Author details}

'Molecular Biology and Biotechnology Department, Human Genetics Division, Atomic Energy Commission, Damascus, Syria. ${ }^{2}$ Jena University
Hospital, Institute of Human Genetics, Jena, Germany. ${ }^{3}$ Molecular Biology and Biotechnology Department, Mammalians Biology Division, Atomic Energy Commission, Damascus, Syria.

\section{Authors' contributions}

AW performed the cytogenetic studies in the present case and collected the data relative to this case report; WA supervised the cytogenetic analysis; AW, EK did the molecular cytogenetic analysis and interpretation; AA did the flow cytometry analysis and AW drafted the paper and all authors contributed to the finalizing of the manuscript. All authors read and approved the final manuscript.

\section{Competing interests}

The authors declare that they have no competing interests.

Received: 15 June 2011 Accepted: 18 August 2011

Published: 18 August 2011

\section{References}

1. Look AT: Molecular Pathogenesis of MDS. Hematology Am Soc Hematol Educ Program 2005, 156-160.

2. Haase D, Steidl C, Schanz J, Schabla R, Pfeilstöcker M, Nösslinger T, Hildebrandt B, Kuendgen A, Lübbert M, Kunzmann B, Giagounidis A, Aul C, Trumper L, Krieger O, Fonatsch C, Valent P, Stauder R, Germing U: Correlation of cytogenetic fi ndings with morphology, clinical course and prognosis in 2124 patients with MDS. Blood 2005, 106, 232A,787.

3. Vundinti BR, Kerketta L, Jijina F, Ghosh K: Cytogenetic study of myelodysplastic syndrome from India. Indian J Med Res 2009, 130:155-159. 
4. Yamamoto $K$, Ito M, Minagawa $K$, Urahama N, Sada A, Okamura A, Matsui T: $A$ der(13)t(7;13)(p13;q14) with monoallelic loss of RB1 and D13S319 in myelodysplastic syndrome. Cancer Genet Cytogenet 2005, 162:160-165.

5. Invernizzi R, Filocco A: Myelodysplastic syndrome: classification and prognostic systems. Oncol Rev 2010, 4:25-33.

6. Mitelman F, Johansson B, Mertens F, (Eds.): Mitelman Database of Chromosome Aberrations in Cancer. 2009 [http://cgap.nci.nih.gov/ Chromosomes/Mitelman"].

7. Fenaux P: Chromosome and molecular abnormalities in myelodysplastic syndromes. Int J Hematol 2001, 73:429-437.

8. Chen Z, Issa B, Brothman LJ, Hendricksen M, Button D, Brothman AR: Nonrandom rearrangements of $6 p$ in malignant hematological disorders. Cancer Genet Cytogenet 2000, 121:22-25.

9. Kao C, Wu SQ, DeVries S, Reznikoff WS, Waldman FM, Reznikoff CA: Carcinogen-induced amplification of SV40 DNA inserted at 9q12-21.1 associated with chromosome breakage, deletions, and translocations in human uroepithelial cell transformation in vitro. Genes Chromosomes Cancer 1993, 8:155-166.

10. Heerema NA, Nachman JB, Sather HN, La MK, Hutchinson R, Lange BJ Bostrom B, Steinherz PG, Gaynon PS, Uckun FM: Deletion of 7p or monosomy 7 in pediatric acute lymphoblastic leukemia is an adverse prognostic factor: a report from the Children's Cancer Group. Leukemia 2004, 18:939-947.

11. David Ng, Ousmane Toure, Ming-Hui Wei, Arthur CDiane, Fatima Abbasi, Laura Fontaine, Marti EGerald, Fraumeni FJoseph Jr, Goldin RLynn, Neil Caporaso, Toro RJorge: Identification of a novel chromosome region, 13q21.33-q22.2, for susceptibility genes in familial chronic lymphocytic leukemia. Blood 2007, 109:916-925.

12. Chui DT, Hammond D, Baird M, Shield L, Jackson R, Jarrett RF: Classical Hodgkin lymphoma is associated with frequent gains of $17 q$. Genes Chromosomes Cancer 2003, 38:126-136.

13. Germing $U$, Hildebrandt $B$, Pfeilstöcker $M$, Nösslinger $T$, Valent $P$, Fonatsch C, Lübbert M, Haase D, Steidl C, Krieger O, Stauder R, Giagounidis AA, Strupp C, Kündgen A, Mueller T, Haas R, Gattermann N, Aul C: Refinement of the international prognostic scoring system (IPSS) by including LDH as an additional prognostic variable to improve risk assessment in patients with primary myelodysplastic syndromes (MDS) Leukemia 2005, 19:2223-2231.

14. AL-achkar W, Wafa A Nweder MS: A complex translocation $t(5 ; 9 ; 22)$ in Philadelphia cells involving the short arm of chromosome 5 in a case of chronic myelogenous leukemia. Journal of Experimental and Clinical Cancer Research 2007, 26:411-415.

15. Shaffer L, Slovak M, Cambell L, (eds): ISCN (2009): An International System for Human Cytogenetic Nomenclature. 2009, S. Karger, Basel.

16. Liehr T, Heller A, Starke H, Rubtsov N, Trifonov V, Mrasek K, Weise A, Kuechler A, Claussen U: Microdissection based high resolution multicolor banding for all 24 human chromosomes. Int J Mol Med 2002, 9:335-339.

doi:10.1186/1755-8166-4-16

Cite this article as: Al-Achkar et al: Biclonal myelodysplastic syndrome involving six chromosomes and monoallelic loss of RB1 - A rare case. Molecular Cytogenetics 2011 4:16.

\section{Submit your next manuscript to BioMed Central and take full advantage of:}

- Convenient online submission

- Thorough peer review

- No space constraints or color figure charges

- Immediate publication on acceptance

- Inclusion in PubMed, CAS, Scopus and Google Scholar

- Research which is freely available for redistribution

Submit your manuscript at www.biomedcentral.com/submit
C Biomed Central 